\title{
Estimating Discards Using Selectivity Data: the Effects of Including Discard Data in Assessments of the Demersal Fisheries in the Irish Sea
}

\author{
J. Casey \\ Ministry of Agriculture, Fisheries and Food, Directorate of Fisheries Research \\ Fisheries Laboratory, Pakefield Road, Lowestoft, Suffolk NR33 OHT, U.K.
}

\begin{abstract}
A model is described to predict the numbers-at-age of fish discarded in fisheries for which only landings-at-age are known. The model assumes a knowledge of the distribution of length within each age group in the population, and uses mesh selection characteristics and an inferred discarding practice, to derive the proportions of each age group discarded and landed. Mesh selectivity and discarding practice, in terms of proportions of the catch discarded and landed, are described using a logistic fit to the proportions of the population entering the net that are caught, discarded and landed. The application of the model is illustrated using data from the mixed demersal fisheries in the Irish Sea, and the effects of including discards in the assessments and on yield-per-recruit are examined. Including discard estimates in the assessment results in increased estimates of stock numbers and increased fishing mortality on age groups that were subject to discarding. As a result the perceived level of exploitation relative to $F_{\max }$ was altered.
\end{abstract}

Key words: Assessment, discards, mesh selectivity, NE Atlantic

\section{Introduction}

Catches of finfish in the Irish Sea are dominated by four main species; the common sole (Solea solea (Linnaeus, 1758)), plaice (Pleuronectes platessa Linnaeus, 1758), cod (Gadus morhua Linnaeus, 1758) and whiting (Merlangius merlangus (Linnaeus, 1758)). The demersal fishery for these species in the Irish Sea is prosecuted by 3 main fleets, each using a different gear type; beam trawlers, otter trawlers and Nephrops trawlers. Each fleet targets a different group of species; beam trawlers target flatfish, otter trawlers target gadoids, and as the name suggests, Nephrops trawlers target Norway lobster (Nephrops norvegicus (Linnaeus, 1758)). However, all three main fleets catch each of the four main finfish species in varying amounts.

Annual single-species assessments for each of these stocks are carried out by the International Council for the Exploration of the Sea (ICES). The methodology used is tuned Virtual Population Analysis (VPA), which is based on fitting a time series of catch-per-unit of effort-at-age data (CPUE), to catches at age from the fishery (Pope and Shepherd, 1988). Reliable estimates of catch-at-age data are fundamental to VPA. Catches from the fishery comprise both landings and discards, the latter being fish which are caught but are not landed for sale. In some fisheries discards are monitored on a regular basis, but the collection of such data is extremely costly, both in time and money. For the
Irish Sea fisheries, landings are routinely monitored and sampled for age composition, but information on the numbers of fish discarded is generally lacking, and for each of these main species, with the exception of whiting, no estimates of discards are available. For whiting, discarding is monitored only in the fishery which targets Norway lobster. The proportions of each age group discarded in this fishery are applied to the other fisheries' landings of Nephrops to give estimates of catches of whiting. As a result, ICES assessments for Irish Sea stocks using VPA, have largely been carried out using landings data alone, and as discarding may account for a significant proportion of the fishing mortality $(F)$ on certain age groups of some species, the estimates of $F$ and the initial population sizes of such age groups will be in error.

This paper describes a method of estimating the level of discard in fisheries for which no observed discard data are available. The method is illustrated for the mixed fishery for sole, plaice, cod and whiting in the Irish Sea. Estimates of discards are made using a selectivity model, and the revised catch-at-age data are used to provide alternative assessments using VPA. In all assessments and predictions presented here, it has been assumed that all discarded fish die, and that all fish escaping the meshes survive. The results are compared with those carried out by ICES. The results are also expressed in terms of yield-perrecruit. 


\section{Methods and Data}

\section{The Model}

The model utilises landings-at-age data from the fishery for each species, together with speciesspecific mesh selectivity parameters, and assumes that the distributions of length-at-age in the population is known or can be inferred.

Distribution of length-at-age in the population. The distribution of length within an age group $a$ in the population for a given time period (e.g. year, month, season) may be obtained by direct observation (e.g. from research vessel surveys) or may be described as a normal distribution with mean length-at-age $\mu_{a}$, and standard deviation $\sigma_{a}$. Writing the normal density function of length-at-age a:

$$
\varnothing_{a}(I)=\frac{1}{\sigma_{a} \sqrt{2 \pi}} e^{\left[-\frac{1}{2}\left\{\frac{1-\mu a}{\sigma_{a}}\right\}^{2}\right]}
$$

The proportion of the population of the $a^{\text {th }}$ age group in the length range $(I, I+\Delta I)$ is given approximately by:

$$
\text { Plla }=\varnothing \mathrm{a}(\mathrm{I}+\Delta \mathrm{I} / 2) \times \Delta \mathrm{I}
$$

In practice we set $P_{1 \mid a}=0$ for:

$$
|+\Delta| / 2 \notin(\mu a \pm 3 \sigma a)
$$

Mesh selectivity. For a given species, the proportions of fish in the length group $(I, I+\Delta I)$ which enter the net and are retained by a given mesh size, may be described using a logistic curve defined using species-specific parameters $\left(L_{50}\right.$ and $\left.L_{25}\right)$ as follows:

$$
\mathrm{S}_{\mathbf{I}}=\{[3\{(\mathrm{~L} 50-(\mathrm{l}+\Delta \mathrm{I} / 2)) /(\mathrm{L} 50-\mathrm{L} 25)\}]+1\}^{-1}
$$

where $S$, is the proportion of the population in the length group $(I, I+\Delta I)$ entering the net that is retained by the meshes.

$L_{50}$ is the length for which the proportion of fish retained is $50 \%$ of those at that length that entered the net.

$L_{25}$ is the length for which the proportion of fish retained is $25 \%$ of those at that length that entered the net.

Estimating the proportions of fish caught. Given the length distribution at age in the sea, and the selection characteristics of the gears used to exploit the population, and assuming all age/length groups are equally susceptible to exploitation, i.e. available for capture, the proportion of each age group a entering the gears and is retained $\left(R_{a}\right)$ is simply the sum over all lengths within an age group, of the product of the proportions at length retained by the mesh $\left(S_{\beta}\right)$, and the proportions at length available for capture $\mathrm{P}_{1 \mid \mathrm{a}}$ as follows:

$$
R_{a}=\sum_{1} S_{1} \times P|| a
$$

Discarding practice. For some species and fisheries, there are data available on discarding practice. In such cases, the proportions at each length retained and discarded are usually based on observations made at sea. In the absence of any information on the discarding practice, it is assumed here that the primary reason for discarding fish which are caught, is to comply with minimum landing size regulations. For some species, particularly those with a high market value, virtually all fish above the legal minimum landing size will be retained for sale, whereas those below the minimum permissible landing size will not appear in the declared landings. Whether such fish are returned to the sea, or landed illegally, they still account for unknown fishing mortality and, in principle, should be included in any assessment. In practice, it is unlikely that the sorting procedure on board vessels will result in knife-edge discarding at the minimum landing size; some undersized fish will be landed to the market and invariably some oversized fish will be discarded. As a result it is assumed here that a sorting ogive may be used to describe the discarding practice, in the same way as for mesh selection as follows:

$$
\mathrm{PLI}=\left\{\left[3\left\{\left(\mathrm{DL}_{50}-(|+\Delta| / 2)\right) /\left(\mathrm{DL}_{50}-\mathrm{DL}_{25}\right)\right\}\right]+1\right\}^{-1}
$$

where $P L_{1} \quad$ - is the proportion of the catch of length group (I) that is retained and landed.

$D L_{50}$ - is the length for which the proportion of fish discarded is $50 \%$ of those of that length that are caught, and is set at the minimum landing size.

$D L_{25}$ - is the length for which the proportion of fish discarded is $25 \%$ of those of that length that are caught, and is set at $0.95 \times D L_{50}$.

The proportion of fish of length $(/)$ which are caught, and are then discarded $(P D)$ is then given by:

$$
P D_{\mid}=1-P L_{\mid}
$$

Estimating catch numbers. Using Equations 2, 3 and 5, the proportions of each age group caught, that are landed and discarded can be estimated. The proportion of the catch of age group a that is landed $\left(P L_{a}\right)$, is the sum over all length groups within that age group, of the product of the 
proportion at each length available for capture $\left(P_{\| l a}\right)$, the proportion of those fish at each length entering the net that are retained by the gears $\left(S_{1}\right)$ and the proportion at each length landed $\left(P L_{1}\right)$. Hence:

$$
P L_{a}=\sum_{1} S_{1} \times P_{\| \mid a} \times P_{\mid}
$$

and the number caught $\left(C_{a}\right)$ is related to the number landed $\left(N L_{a}\right)$ as follows:

$$
\mathrm{CN}_{\mathrm{a}}=\mathrm{NL}_{\mathrm{a}} \times \frac{1}{\mathrm{PL}_{\mathrm{a}}}
$$

The number discarded at age is given by:

$$
\mathrm{DN}_{\mathrm{a}}=\mathrm{CN}_{\mathrm{a}}-\mathrm{NL}_{\mathrm{a}}
$$

Hence for a species, given the landings in number-at-age, the mesh selectivity parameters and an estimate of discarding practice, it is possible to derive estimates of the catch in numbers-at-age (Equation 8, via 7, 5 and 3).

Alternatively, if the distribution of numbers of length-at-age of the landings is known $\left(\left.\mathrm{NL}_{\|}\right|_{\mathrm{a}}\right)$ the catch-at-age data may be estimated by multiplying the landings numbers-at-length by the reciprocal of the proportions landed at length $\left(\mathrm{PL}_{\mid}\right)$from equation 5, and summing over all length groups within each age group; i.e.:

$$
\mathrm{CN}_{\mathrm{a}}=\sum_{\uparrow}\left(\mathrm{NL}_{\|} / \mathrm{a} / \mathrm{PL}_{1}\right)
$$

It also follows that if the length distributions of the catch-at-age data are known, then landings and discards at each length and age may be estimated using the respective proportions landed and discarded from Equations 5 and 6 .

A major drawback to either of these approaches is that the discards cannot be estimated for length groups smaller than the smallest in the landings (see Discussion).

Calculation of mean weight-at-age in the catches. In addition to providing estimates of the proportions of the catch landed and discarded, the mean weight of landings, discards and catch may also be calculated. Mean weight-at-age in the catch $\left(W C_{a}\right)$ is calculated using:

$$
W C_{a}=\frac{\sum_{1} S_{1} \times P_{1 \mid a} \times W_{1}}{\sum_{1} S_{1} \times P_{\| a}}
$$

where $W_{I}=$ mean weight of length group $I$, and is calculated from the relationship:

$$
w=a \times 1^{b}
$$

Similarly mean weight-at-age in the landings $\left(W L_{a}\right)$ is obtained from:

$$
W L_{a}=\frac{\sum_{P} L_{\mid} \times S_{\mid} \times P_{|| a} \times W_{\mid}}{\sum_{1} \mathrm{PL}_{\mid} \times S_{\mid} \times P_{|| a}}
$$

and mean weight-at-age of discards $\left(W D_{a}\right)$ is:

$$
W D_{a}=\frac{\sum_{1} P D_{\mid} \times S_{\mid} \times P_{|| a} \times W_{\mid}}{\sum_{1} P D_{\mid} \times S_{\mid} \times P_{|| a}}
$$

\section{Application of the model}

All basic data for the assessments and predictions relate to years prior to and including 1989. For each species, landings-at-age from the Irish Sea fisheries were obtained from the 1990 Report of the ICES Irish Sea and Bristol Channel Working Group (Anon., MS 1991a). International landings at age data for 1989 were partitioned into landings-at-age by fleet according to estimates provided by working group members. Where fleet disaggregated landings numbers-at-age were not available, estimates were derived using the landings-at-age composition for the most similar fleet, and raised to the relevant landings weight. Since estimates of fleet disaggregated landings-atage data were available for 1989 only, the relative proportions of each age group caught by the different fleets were then used to partition the international landings-at-age data for years prior to 1989.

The 1989 landings-at-age data were converted to catches-at-age using the results of the selectivity model described above. For age groups considered to be fully selected by the Irish Sea fleets (i.e. those age groups too large to escape current mesh sizes), mean length-at-age in the population was calculated from mean weights-at-age in the catches given in Anon. (MS 1991a) and converted to length using published length-weight relationships (Bedford et al., 1986).

Normal distributions of length-at-age were described using the normal distribution function described above (Equation 2), setting standard deviation of length-at-age equal to $10 \%$ of mean length. For partially selected age groups, mean and standard deviation of length-at-age were obtained from English research vessel sampling in the Irish Sea (D. J. Symonds, Ministry of Agriculture, Fisheries and Food, Directorate of Fisheries Research, Fisheries Laboratory, pers. comm.), and distribution of length-at-age was described using these parameters and the normal distribution function. The assumed mean lengths-at-age in the populations used are given in Table 1.

Proportions of each age group of each species entering the nets that are caught by each fleet were 
estimated using the estimated distributions of length-at-age in the population derived from means and standard deviations given in Table 1, together with mesh sizes in use in 1989 and appropriate selectivity parameters (Table 2). Selectivity parameters are those given by Wileman (1988). The distribution of size at age in the populations was assumed to remain constant from year to year, hence the proportions of each age group entering the nets that were caught also remained constant. Similarly constant proportions of those fish caught were assumed to be landed and discarded. Using the assumed discarding practice for each species, proportions landed and discarded were calculated.

For each year that landings-by-age data were available, the number-at-age landed by species were raised to numbers caught using Equation 8. These data were then used as input to VPA. Fleet data used to tune each of the VPAs was also treated in the same way, with the landings numbers being raised by the appropriate proportions landed for the mesh size used by the tuning fleets. Whiting were treated rather differently since estimates of discards were included in the VPA input tables in the ICES report (Anon., MS 1991a). The catch-at-age data were first converted to landings-at-age by subtracting the estimated discards provided in the ICES report from the catches. New estimates of discards were then calculated using the results of the selectivity model.

For each stock, with the exception of whiting, VPA using the revised catch-at-age data was carried out in exactly the same way as in the ICES assessments. For whiting the input catch-at-age range was reduced to exclude 0-group catches, and two assessments were made; one using the catch estimates provided in the ICES report, and a second using the revised catch estimates resulting from the selectivity model. Exclusion of the 0-groups was necessary since no 0-group whiting were reported as being landed in the ICES report, and as a result no estimate of catch could be made using this selectivity model.

Long-term equilibrium yield-per-recruit (YPR, Beverton and Holt, 1957) calculations were carried using the results of the revised assessments and those made by ICES. For each stock, $F$ at age in the starting year (1990) was derived from the relevant VPA, by taking the mean values over the

TABLE 1. Mean and standard deviations of length-at-age $(\mathrm{cm})$ in the populations used in the selectivity model. Values are only presented for the age ranges used in the assessments.

\begin{tabular}{|c|c|c|c|c|c|c|c|c|}
\hline \multirow[b]{2}{*}{ Age } & \multicolumn{2}{|c|}{ Sole } & \multicolumn{2}{|c|}{ Plaice } & \multicolumn{2}{|c|}{ Whiting } & \multicolumn{2}{|c|}{ Cod } \\
\hline & Mean & S. dev. & Mean & S. dev. & Mean & S. dev. & Mean & S. dev. \\
\hline 1 & & & 17.28 & 1.86 & 22.85 & & 44.18 & 4.42 \\
\hline 2 & 19.05 & 1.78 & 22.44 & 2.30 & 30.53 & 3.05 & 61.75 & 6.17 \\
\hline 3 & 22.52 & 3.05 & 26.94 & 3.15 & 36.70 & 3.67 & 75.15 & 7.52 \\
\hline 4 & 25.46 & 2.97 & 30.86 & 3.09 & 41.65 & 4.16 & 85.38 & 8.54 \\
\hline 5 & 27.93 & 2.79 & 34.29 & 3.43 & 45.62 & 4.56 & 93.20 & 9.32 \\
\hline 6 & 30.02 & 3.00 & 37.29 & 3.73 & 48.81 & 4.88 & 99.16 & 9.92 \\
\hline 7 & 31.78 & 3.18 & 39.90 & 3.99 & 51.37 & 5.14 & 103.71 & 10.37 \\
\hline 8 & 33.26 & 3.33 & 42.18 & 4.22 & 53.42 & 5.34 & & \\
\hline 9 & 34.52 & 3.45 & 44.17 & 4.42 & & & & \\
\hline 10 & 35.57 & 3.56 & & & & & & \\
\hline
\end{tabular}

TABLE 2. Minimum landing sizes (MLS), selectivity parameters and length-weight relationships for each stock. Selection range is $L_{75}-L_{25}$.

\begin{tabular}{|c|c|c|c|c|c|}
\hline & & Sole & Plaice & Cod & Whiting \\
\hline MLS (cm) & & 24 & 25 & 35 & 27 \\
\hline Selection factor & & 3.2 & 2.2 & 3.1 & 3.3 \\
\hline Selection range & & 4.7 & 30.0 & 6.3 & 8.5 \\
\hline Length-weight relationship & a & 0.009 & 0.0123 & 0.0124 & 0.004 \\
\hline$w=a^{*} / b$ & $\mathrm{~b}$ & 3.034 & 2.97 & 2.96 & 3.21 \\
\hline
\end{tabular}


period 1987-89, scaled to the 1989 reference $F$ (mean F over a specified age range). These values were partitioned into partial Fs at age by fleet using the respective catch numbers-at-age in 1989 . Furthermore they were also partitioned into $F$ due to landings and to discards, using the relevant proportions landed and discarded estimated by the model for each fleet.

\section{Results}

\section{Assessments}

The results of the VPA runs using the revised catch-at-age data from the selectivity model together with those of the ICES assessments are illustrated in Fig. 1 to 3. Results for cod are not the original ICES assessment (Anon., MS 1991a). Presentation of the results has been restricted to comparisons between trends in mean fishing mortality over specific age ranges (reference F), spawning stock biomass (SSB), recruitment and mean fishing mortality-at-age over the period 198789 (mean F). For sole (Fig. 1) and whiting (Fig. 3) the trends in reference $F, S S B$ and recruitment were essentially the same for both the ICES and the revised assessment, each being slightly higher in the revised assessment. The results for plaice (Fig. 2) were similar, except that recruitment for the years 1977 and 1989 appeared significantly higher in the revised assessment than in the ICES assessment. presented since these remained unchanged from

The 1989 values for recruitment were of course poorly defined in the VPA, which may explain this discrepancy. The 1977 value was a result of the extremely high catch numbers of 1 year old plaice in that year (an order of magnitude greater than the next highest observed catches of 1-groups), which was not reflected in the catch of the 1976 year-class as 2 year olds in 1978 .

Examination of the mean exploitation patterns for each species indicated that for sole (Fig. 1d), the effect of including discard estimates in the assessment was relatively small, but that mean fishing mortality on age 2 to 4 was slightly increased. For whiting, (Fig. 3d), it appeared that mean $F$ on age group 1 was increased in the revised assessment whereas, for age group 2, there appeared to be a slight reduction in mean $F$ compared to the ICES assessment. The results of the revised VPA on the mean exploitation pattern for plaice (Fig. 2d) are rather more dramatic. Mean $F$ on ages 1 to 3 were significantly increased, reflecting the high level of discarding predicted by the selectivity model.

\section{Long-term yield}

Comparisons of yield-per-recruit analyses between the results of the ICES assessments and the revised assessments were carried out using the mean exploitation patterns generated by each assessment. Mean F-at-age for landings, discards
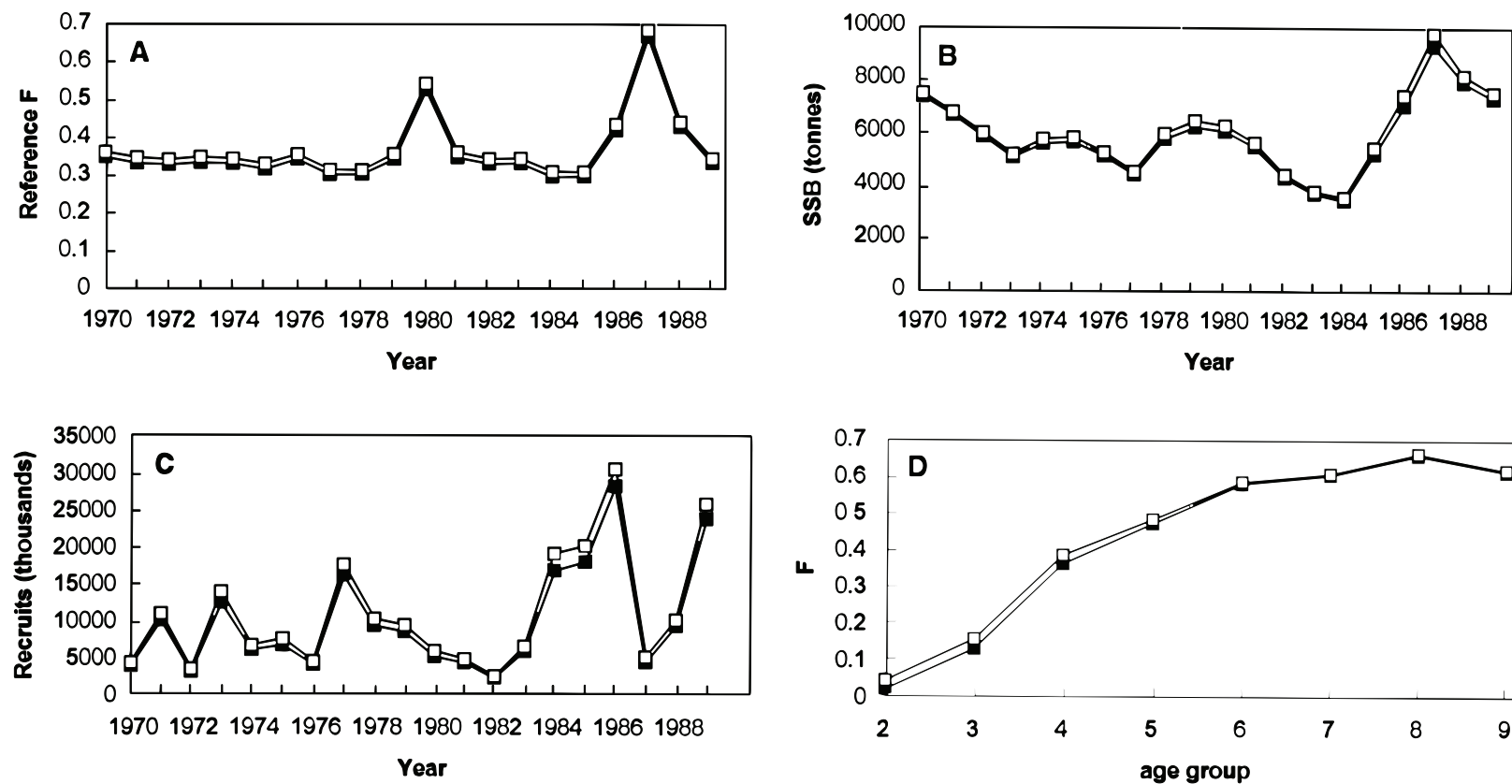

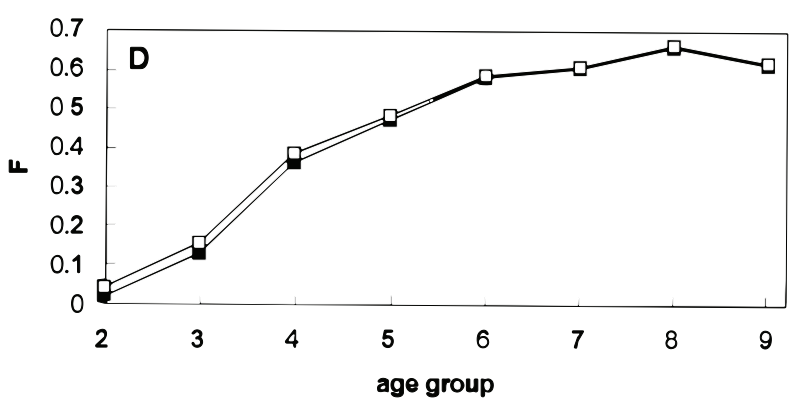

Fig. 1. Selected results of assessments for sole: a) Trends in reference mean fishing mortality on age groups 3-9 inclusive. b) Trends in spawning stock biomass (SSB). c) Trends in recruitment (age 2). d) Mean fishing mortality at age (1987-89). Solid squares indicate results of ICES assessment. Open squares indicate results of revised assessment including estimated discards. 

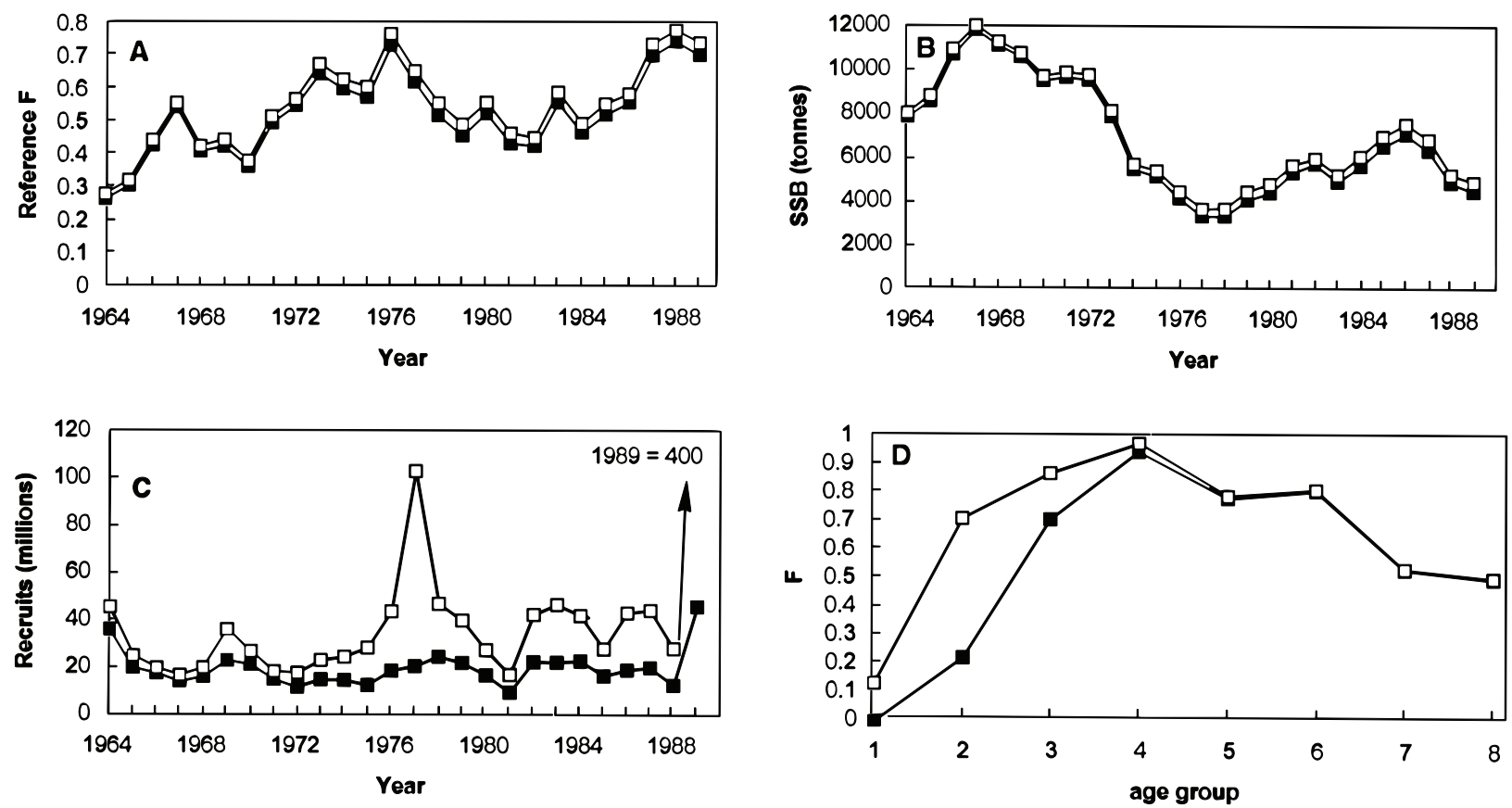

Fig. 2. Selected results of assessments for plaice: a) Trends in reference mean fishing mortality on age groups 3-8 inclusive. b) Trends in spawning stock biomass (SSB). c) Trends in recruitment (age 1). d) Mean fishing mortality at age (1987-89). Solid squares indicate results of ICES assessment. Open squares indicate results of revised assessment including estimated discards.
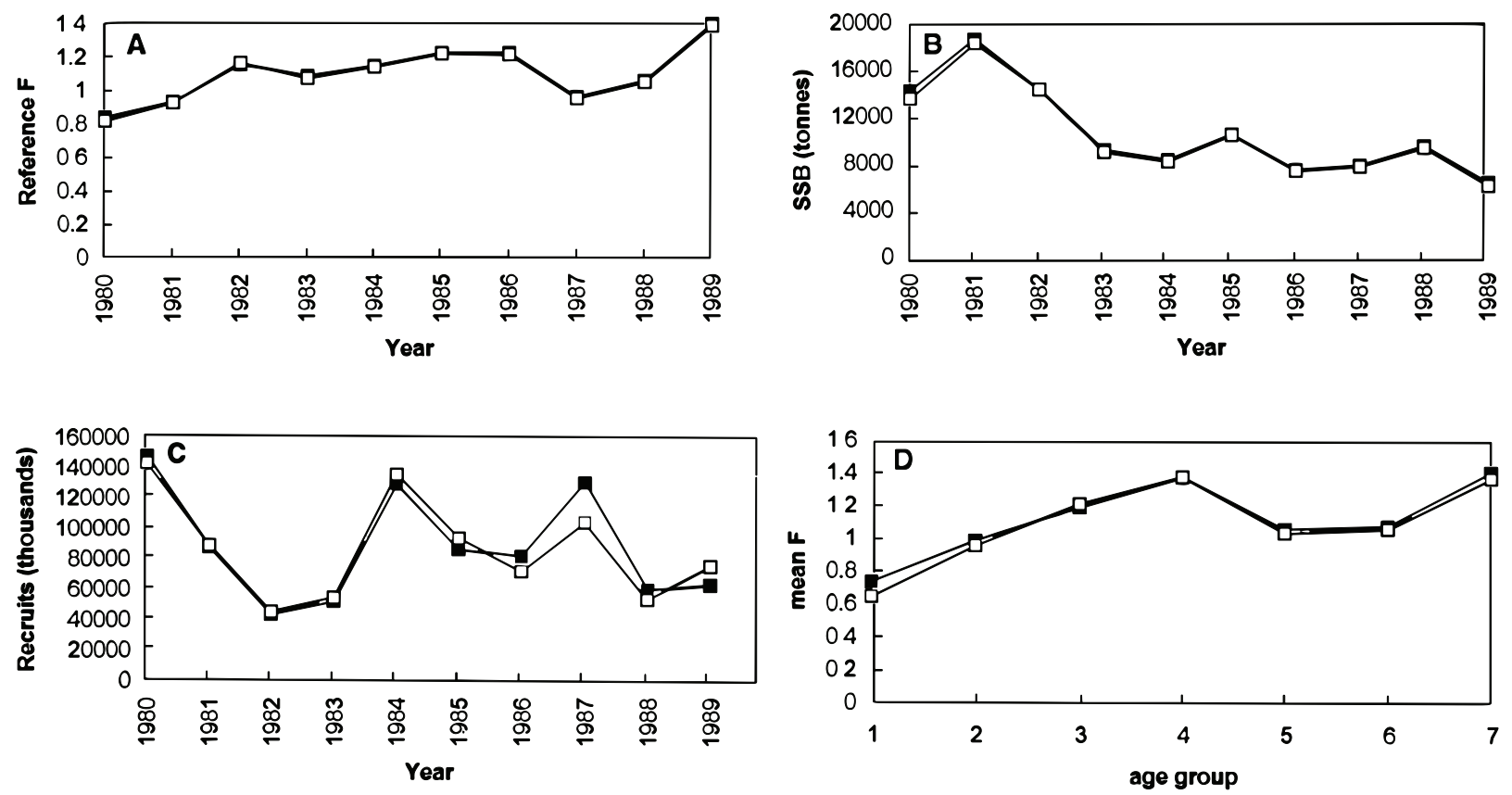

Fig. 3. Selected results of assessments for whiting: a) Trends in reference mean fishing mortality on age groups 2-6 inclusive. b) Trends in spawning stock biomass (SSB). c) Trends in recruitment (age 1). d) Mean fishing mortality at age (1987-89). Solid squares indicate results of ICES assessment. Open squares indicate results of revised assessment including estimated discards. 
and catch estimated by the selectivity model, by species and fleet are given in Table 3 , and associated mean weights-at-age estimated by the model are presented in Table 4. Note that in this model, mean weights in the catches are unaffected by levels of $F$, and are determined only by mesh selectivity. Input exploitation patterns and mean weights-at-age for each species derived from the ICES assessment are given in Anon. (MS 1991a).

The results are presented in Fig. 4 to 6. A direct comparison between the absolute values of landings- and spawning stock biomass-per-recruit, resulting from the different assessments was inappropriate, since the equilibrium recruitment differed depending on whether discards were included in the assessment. It was possible, however, to compare the current level of exploitation in relation to $F_{\text {max }}$, the level that gives maximum sustainable yield (MSY).

For sole (Fig. 4) and whiting (Fig. 6), the overall shape of the yield curves was quite similar regardless of whether discards were included or excluded from the assessment, and it appeared that $F_{\text {max }}$ was about $20 \%$ and $10 \%-20 \%$ of the current exploitation level, respectively. For plaice, however, the results were quite different. The landingsper-recruit curves derived from the two assessments were markedly different in shape. The ICES curve was relatively flat-topped indicating that reducing or increasing the exploitation rate would have little effect on landings in the long term. However, the curve resulting from the revised assessment (including discards) showed a marked peak at 20\%$30 \%$ of the current exploitation level and indicated that there were significant long-term benefits to be had, in terms of yield-per-recruit, if the current exploitation level were to be reduced. Clearly, for plaice at least, the perception of the exploitation rate is highly dependent on whether discards are included in the assessment.

\section{Discussion}

In this paper a model to predict the likely level of discarding in fisheries for which no observed discard data are available has been described and applied to the mixed demersal fisheries in the Irish Sea. The model, is relatively simple but is dependent on a number of parameters. First, the model assumes that the distribution of size-at-age in the population available for capture is known. Second, that species-specific gear selectivity parameters are available. These parameters are fundamental to predicting the proportions of fish entering the net that are caught. Third, in order to use the model to predict the proportion of the catches that are landed and discarded, assumptions about the discarding practices must be made.

It was assumed that discarding takes place primarily in order to comply with minimum landing size regulations and that, the discarding practice can be described as a logistic function about a mean discarding length equivalent to the minimum landing size and a discarding range corresponding to $10 \%$ of the mean; as a result, some undersized fish will be considered as landings and some fish above the minimum landing size will be discarded. Such assumptions may not be wholly appropriate for some species, especially those species which command a high price on landing. Furthermore, it is known that discarding takes place for a variety of reasons other than to comply with minimum landing size regulations and that no account of such discarding has been taken into account in this analysis.

In this paper only annual catch-at-age data were dealt with and the estimated discards were calculated using annual landings-at-age data from the fishery. Clearly there is scope for improvement here, since it would be more appropriate to take into account factors such as spatial and seasonal distribution of the stocks and fisheries, and in particular the seasonal distribution of different age groups of fish in relation to fleet activity. In addition, for all species, and in particular fast-growing species, the size-at-age in the population throughout the year will change and may also vary between years. Furthermore, the model does not incorporate any size selection accounting (see Horwood, 1993). Hence, in this analysis, size-at-age in the available population remains constant. This assumption not only affects the proportions of fish caught, landed and discarded but will also affect the predicted mean weights of landings and discards.

Nevertheless, the application of the model to the Irish Sea fisheries has given some insight into the possible level of discarding. The magnitude of the numbers of fish discarded may not be precise because of the problems outlined above, but discarding of some catches undoubtedly takes place, and is not accounted for in some assessments. Although there are no data to compare the predicted discard levels of sole, plaice and cod, some discard estimates for whiting in the Irish Sea are available. It is interesting to compare the whiting assessments made by ICES with those carried out in this paper. In terms of mean fishing mortality (Fig. 3d), both assessments produce similar exploitation patterns. 


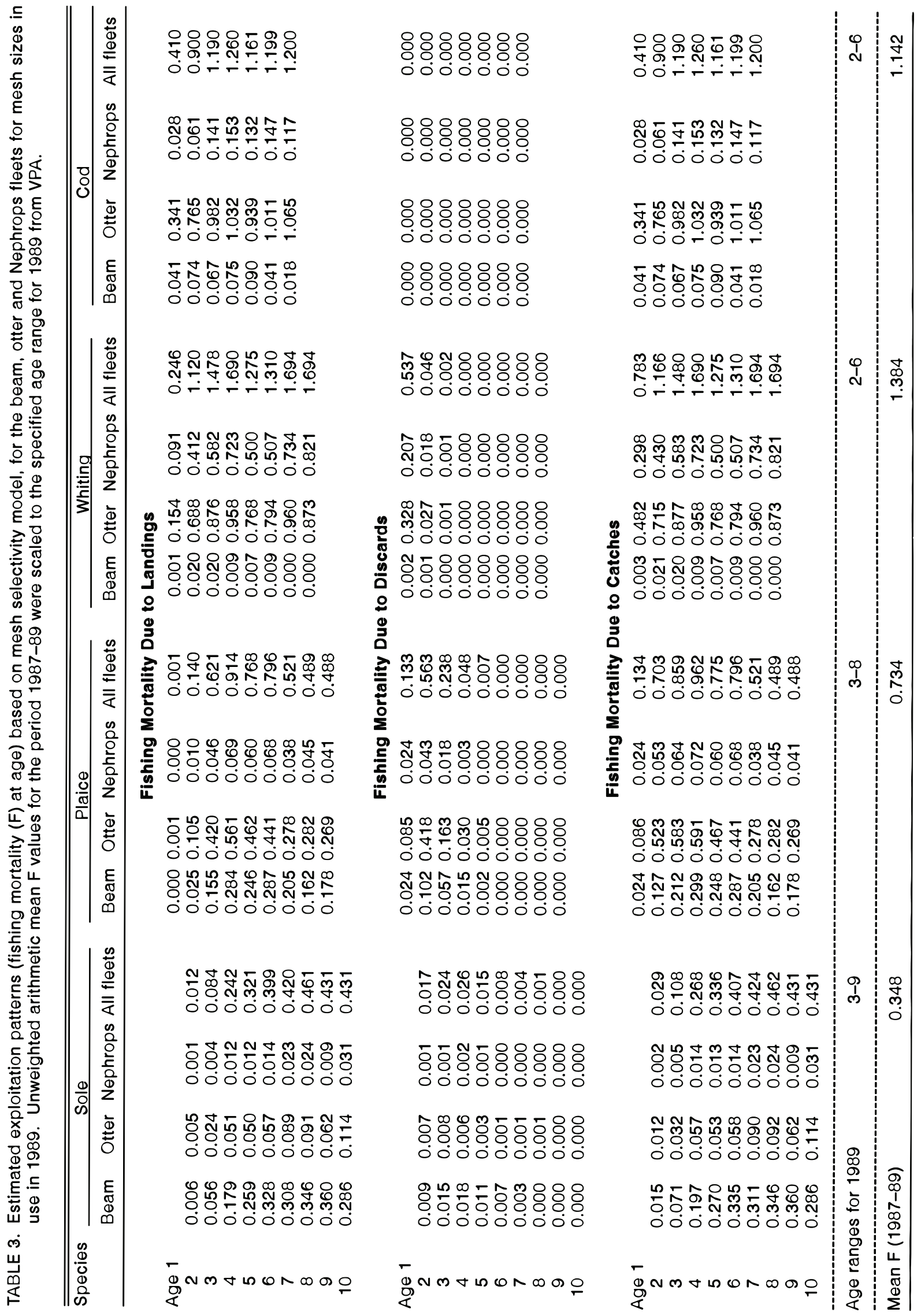




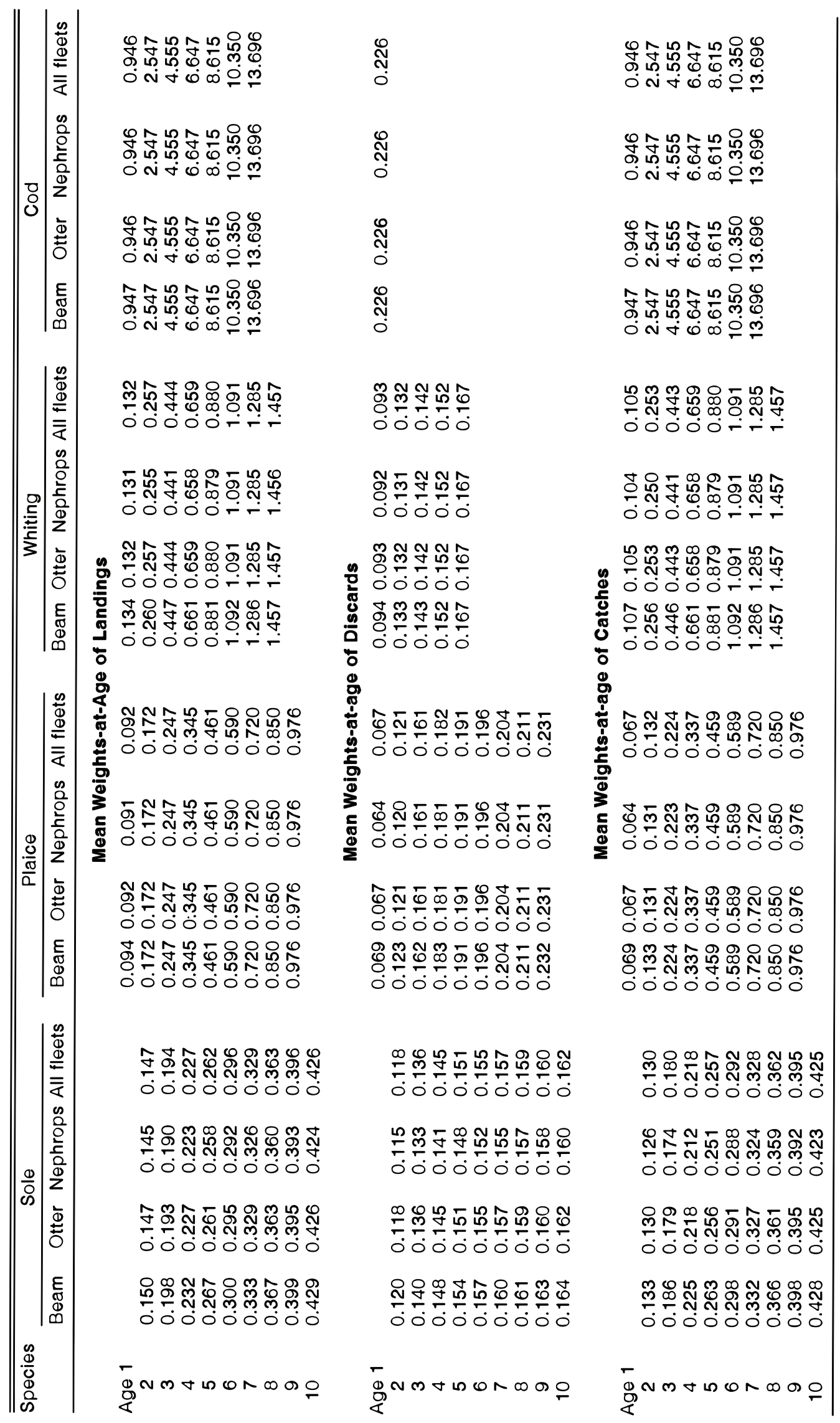




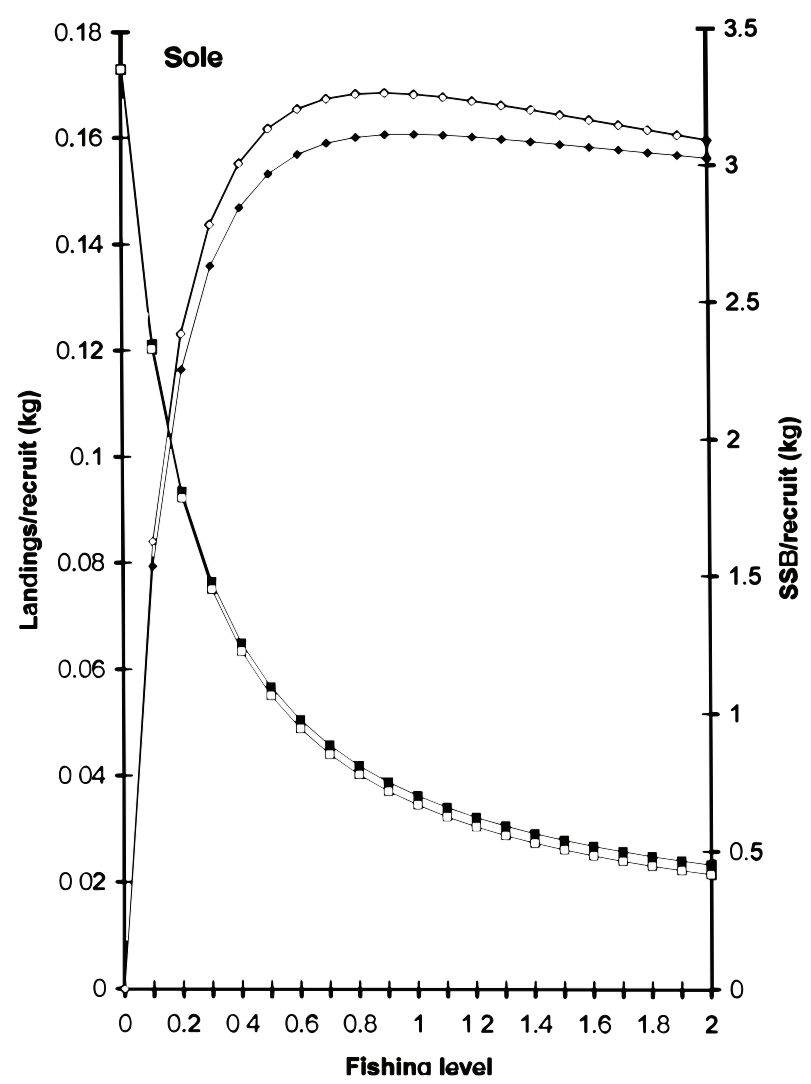

Fig. 4. Yield-per-recruit and spawning stock biomassper-recruit analysis results for sole. Fishing level expresses reference fishing mortality relative to the 1989 level from VPA. Closed diamonds indicate landings predicted from the ICES assessment; open diamonds indicate landings predicted from the revised assessment including estimated discards; closed squares indicate spawning stock biomass predicted from the ICES assessment; open squares indicate spawning stock biomass predicted from the revised assessment including estimated discards.

The general results of the revised assessments are that, including estimates of discards in assessments results in increased fishing mortality rates and increases in stock in number for partially selected age groups. This is perhaps not surprising, but what is not obvious, is what effect the changed exploitation patterns and stock number increases will have on the perception of the current exploitation rates and hence on catch predictions. These points undoubtedly merit consideration and were addressed by the ICES Working Group on Methods of Fish Stock Assessments in 1985 and an overview of assessment calculations in relation to discards was included in the report of that meeting (Anon., 1985).

Perhaps the most striking results in this paper are the differences in yield-per-recruit analyses

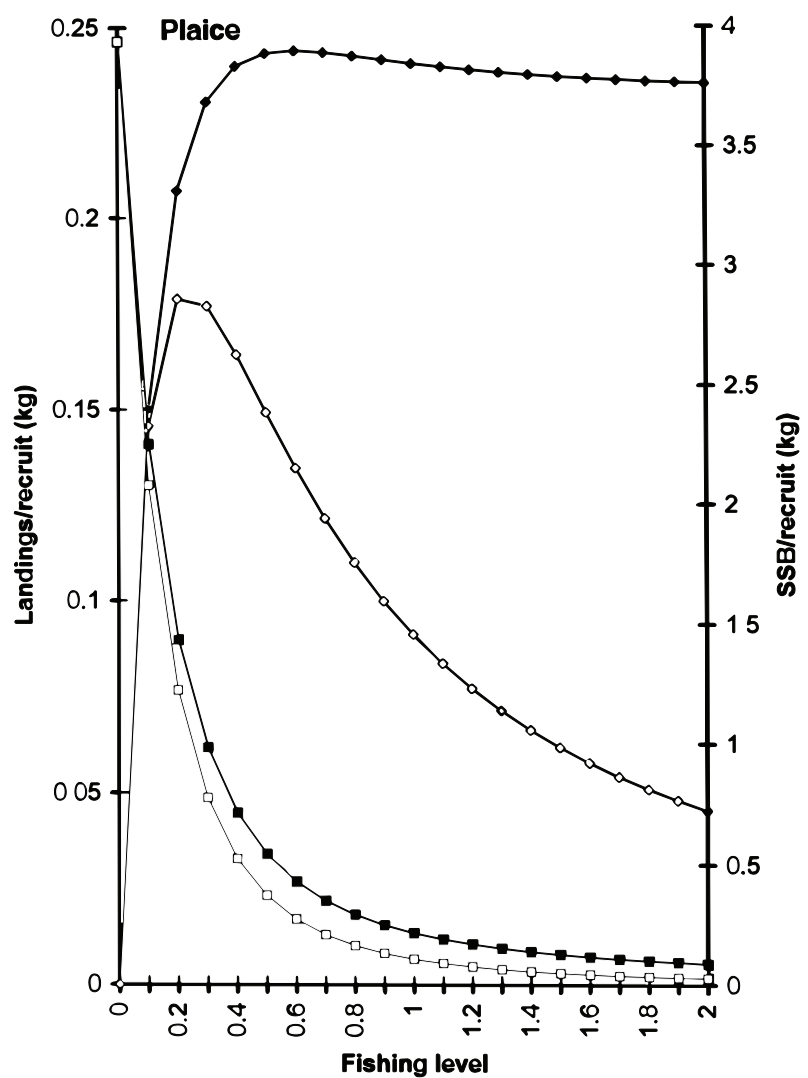

Fig. 5. Yield-per-recruit and spawning stock biomassper-recruit analysis results for plaice. Fishing level expresses reference fishing mortality relative to the 1989 level from VPA. Closed diamonds indicate landings predicted from the ICES assessment; open diamonds indicate landings predicted from the revised assessment including estimated discards; closed squares indicate spawning stock biomass predicted from the ICES assessment; open squares indicate spawning stock biomass predicted from the revised assessment including estimated discards.

carried out for plaice, comparing the results of the ICES assessment with that obtained including estimates of discards (Fig. 5). The perceived differences in the yield-per-recruit curves are due to the changes in the exploitation patterns generated by including estimates of discards in the VPA, with the major source of fishing mortality on the youngest ages being attributable to discarding. Ignoring the fishing mortality due to discards can give an erroneous perception of the current exploitation level. If catch predictions involving changes in technical measures e.g. increases in mesh size are to be considered, the inclusion of discards in the assessments becomes even more important. A small increase in mesh size can result in fewer small fish being caught and discarded, but may not affect the numbers landed. In such circumstances, if predictions are carried out using 


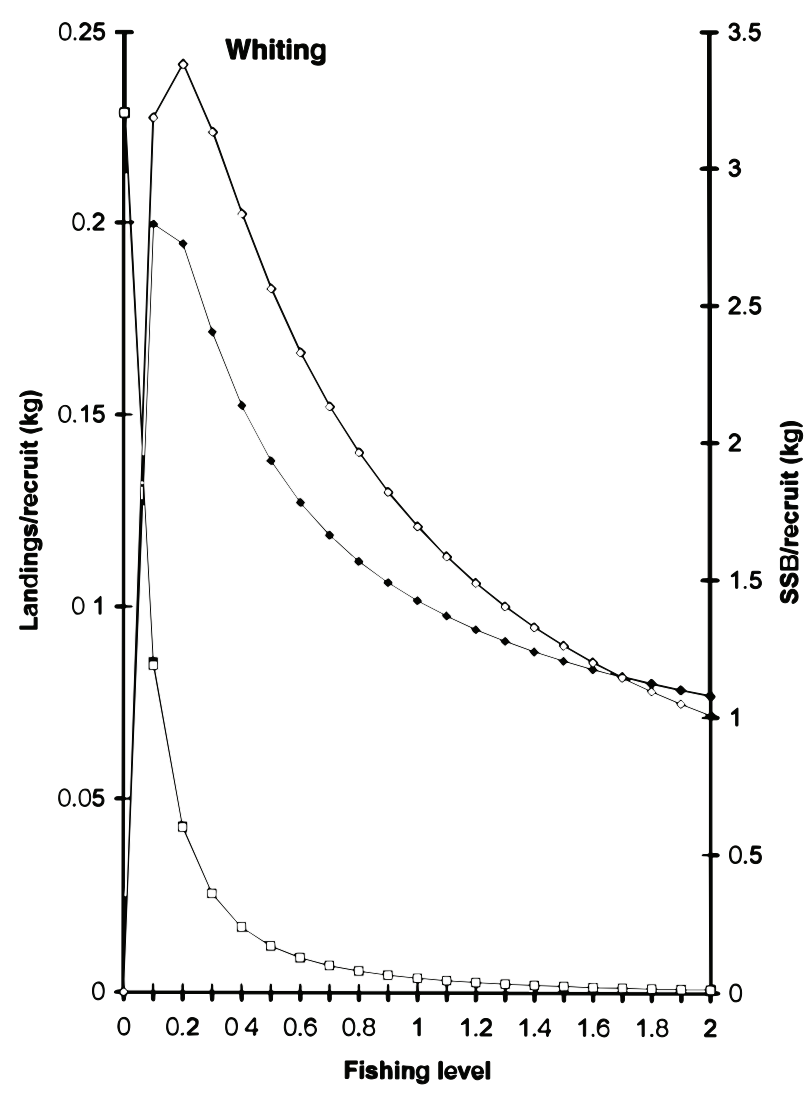

Fig. 6. Yield-per-recruit and spawning stock biomassper-recruit analysis results for whiting. Fishing level expresses reference fishing mortality relative to the 1989 level from VPA. Closed diamonds indicate landings predicted from the ICES assessment; open diamonds indicate landings predicted from the revised assessment including estimated discards; closed squares indicate spawning stock biomass predicted from the ICES assessment; open squares indicate spawning stock biomass predicted from the revised assessment including estimated discards.

the results of an assessment based on landings only, no detectable benefit would be seen from the increase in mesh size. The importance of including discards in technical interactions assessments and predictions has been clearly demonstrated by the ICES Working Group on Fishery Units in Sub-areas VII and VIII (Anon., MS 1991b)

A major drawback with the model is that discards can only be estimated for those sizes of fish that are represented in the landings. A further drawback is the assumption that all age groups are equally available for capture. In practice, although discards are likely to be high at certain times of the year and in certain areas, fishing effort may not be directed equally at all age groups at all times of the year and seasonal discard rates may be quite different. This is especially true for North Sea haddock, where it has been necessary to carry out seasonal catch predictions in order to take into account differential discarding rates of 0 - and 1-group individuals (C. T. Macer and R. A. Ayres, Ministry of Agriculture, Fisheries and Food, Directorate of Fisheries Research, Fisheries Laboratory, unpublished data). It is also important to remember that, in these analyses, all discards are assumed to die.

The results presented in this paper indicate that discarding could be a significant source of fishing mortality on some age groups and that their inclusion in assessments and predictions may be extremely important, since it can affect the perception of appropriate management strategies. With the increase in interest in the use of technical measures including mesh size changes to manage stocks in the Northeast Atlantic, the problem of obtaining discard estimates will need to be addressed by assessment scientists and fishery managers. Discard data are difficult and expensive to collect but if the parameters required for the model presented here can be adequately defined, it may be possible to use such an approach as an alternative to wholesale discard monitoring programs.

\section{Acknowledgements}

I am grateful to numerous colleagues in Lowestoft and elsewhere who assisted in the collation and processing of data for this study. In particular, S. Warnes, W. A. Dawson and the members of the 1990 Irish Sea and Bristol Channel Working Group, notably, R. Briggs, P. Connolly and S. Flatman. D. J. Symonds, M. R. Vince, P. A. Large and M. J. Boon were also kind enough to spare their time to direct me to appropriate data sets. I thank J. W. Horwood and B. W. Jones, for their encouragement and constructive comments on the manuscript, and C. T. Macer for helpful discussions and comment. Mike Nicholson gave me invaluable assistance with the mathematical description of the model, although any shortcomings in the methodology are mine alone. Finally, I would like to thank two anonymous referees for taking so much time to provide excellent reviews of the draft manuscript and Steve Murawski for his encouragement and patience.

\section{References}

ANON. 1985. Report of the ICES Working Group on Methods of Fish Stock Assessment. ICES Coop. Res. Rep. No. 133, 56 p.

MS 1991a. Report of the Irish Sea and Bristol Channel Working Group. ICES C. M. 1990/Assess: 1, $234 \mathrm{p}$.

MS 1991b. Report of the ICES Working Group on Fisheries Units in Sub-areas VII and VIII. ICES C. M. 
1991/Assess: 24, 215 p

BEDFORD, B. C., L. E. WOOLNER, and B. W. JONES. 1986. Length-weight relationships for commercial fish species and conversion factors for various presentations. Fisheries Research Data Report, MAFF, Directorate of Fisheries Research, Lowestoft, No. 10, $41 \mathrm{p}$.

BEVERTON, R. J. H., and S. J. HOLT. 1957. On the dynamics of exploited fish populations. Fish. Invest., Lond., Series II, XIX, 1-533.
HORWOOD, J. W. 1993. The Bristol Channel Sole (Solea solea (L.)): A Fisheries Case Study. Adv. Mar. Biol., 29: 215-367.

POPE, J. G., and J. G. SHEPHERD. 1988. A comparison of the performance of various methods for tuning VPAs using effort data. ICES J. Cons., 40: 176-184.

WILEMAN, D. 1988. Codend Selectivity: A Review of Available Data. Appendix 1: Codend Selectivity Measurements for North Sea Species. Hirtsals, Danish Fisheries Technology Institute. Unpaginated. 